Cochrane Database of Systematic Reviews

\title{
Anticoagulation for cerebral venous sinus thrombosis (Review)
}

Coutinho J, de Bruijn SFTM, deVeber G, Stam J

Coutinho J, de Bruijn SFTM, deVeber G, Stam J.

Anticoagulation for cerebral venous sinus thrombosis.

Cochrane Database of Systematic Reviews 2011, Issue 8. Art. No.: CD002005.

DOI: 10.1002/14651858.CD002005.pub2.

www.cochranelibrary.com 
TABLE OF CONTENTS

HEADER 1

ABSTRACT

PLAIN LANGUAGE SUMMARY

BACKGROUND

OBJECTIVES

METHODS

RESULTS

DISCUSSION

AUTHORS' CONCLUSIONS

ACKNOWLEDGEMENTS

REFERENCES

CHARACTERISTICS OF STUDIES

DATA AND ANALYSES

Analysis 1.1. Comparison 1 Overall benefit or harm of (LMW) heparin, Outcome 1 Death.

Analysis 1.2. Comparison 1 Overall benefit or harm of (LMW) heparin, Outcome 2 Death or dependency.

Analysis 2.1. Comparison 2 Haemorrhagic adverse events, Outcome 1 Symptomatic intracerebral haemorrhage (new or increased).

Analysis 2.2. Comparison 2 Haemorrhagic adverse events, Outcome 2 Any severe haemorrhage.

APPENDICES

FEEDBACK

WHAT'S NEW

HISTORY

CONTRIBUTIONS OF AUTHORS 
[Intervention Review]

\section{Anticoagulation for cerebral venous sinus thrombosis}

Jonathan Coutinho ${ }^{1}$, Sebastiaan FTM de Bruijn², Gabrielle deVeber ${ }^{3}$, Jan Stam ${ }^{1}$

1Department of Neurology, Academic Medical Centre, University of Amsterdam, Amsterdam, Netherlands. 2Department of Neurology, HagaHospital, The Hague, Netherlands. ${ }^{3}$ Division of Neurology, Hospital for Sick Children, Toronto, Canada

Contact address: Jan Stam, Department of Neurology, Academic Medical Centre, University of Amsterdam, Meibergdreef 9, Amsterdam, 1105 AZ, Netherlands. j.stam@amc.uva.nl.

Editorial group: Cochrane Stroke Group

Publication status and date: New search for studies and content updated (no change to conclusions), comment added to review, published in Issue 8, 2011.

Citation: Coutinho J, de Bruijn SFTM, deVeber G, Stam J. Anticoagulation for cerebral venous sinus thrombosis. Cochrane Database of Systematic Reviews 2011, Issue 8. Art. No.: CD002005. DOI: 10.1002/14651858.CD002005.pub2.

Copyright ( 2011 The Cochrane Collaboration. Published by John Wiley \& Sons, Ltd.

\section{A B S T R A C T}

\section{Background}

Treatment of cerebral venous sinus thrombosis with anticoagulants has been controversial. Anticoagulants may prevent new venous infarcts, neurologic deterioration and pulmonary embolism but may also promote haemorrhages.

\section{Objectives}

To assess the effectiveness and safety of anticoagulant therapy in patients with confirmed cerebral venous sinus thrombosis.

\section{Search methods}

We searched the Cochrane Stroke Group Trials Register (last searched August 2010), MEDLINE (1950 to August 2010), EMBASE (1980 to August 2010) and the Cochrane Central Register of Controlled Trials (The Cochrane Library, 2011 Issue 1). In an effort to identify further published, unpublished and ongoing trials we searched ongoing trials registers and reference lists of relevant articles, and contacted authors.

\section{Selection criteria}

Unconfounded randomised controlled trials in which anticoagulant therapy was compared with placebo or open control in patients with cerebral venous sinus thrombosis (confirmed by intra-arterial contrast, or venography with magnetic resonance, or venography with computed tomography imaging).

\section{Data collection and analysis}

Two review authors independently extracted outcomes for each of the two treatment groups (anticoagulant treatment and control). The outcome data for each patient were analysed in the treatment group to which the patient was originally allocated (intention-to-treat analysis). We calculated a weighted estimate of the treatment effects across trials (relative risk, absolute risk reduction).

\section{Main results}

We included two small trials involving 79 patients. One trial (20 patients) examined the efficacy of intravenous, adjusted dose unfractionated heparin. The other trial (59 patients) examined high dose, body weight adjusted, subcutaneous, low-molecular weight heparin (nadroparin). Anticoagulant therapy was associated with a pooled relative risk of death of 0.33 ( $95 \%$ confidence interval (Cl) 0.08 to 1.21 ) and of death or dependency of $0.46(95 \% \mathrm{Cl} 0.16$ to 1.31$)$. The absolute reduction in the risk of death or dependency was $13 \%(95 \%$ $\mathrm{Cl} 30 \%$ to -3\%). No new symptomatic intracerebral haemorrhages were observed. One major gastro-intestinal haemorrhage occurred after anticoagulant treatment. Two control patients (placebo) had a diagnosis of probable pulmonary embolism (one fatal). 


\section{Authors' conclusions}

Based upon the limited evidence available, anticoagulant treatment for cerebral venous sinus thrombosis appeared to be safe and was associated with a potentially important reduction in the risk of death or dependency which did not reach statistical significance.

\section{PLAIN LANGUAGE SUMMARY}

\section{Anticoagulation for cerebral venous sinus thrombosis}

Blood thinning (anticoagulant) drugs may be beneficial for patients with clotting of the veins that surround the brain (sinus thrombosis). Sinus thrombosis is a rare condition where blood clots form in the veins that drain blood from the brain. However, anticoagulant drugs, which are often used to treat sinus thrombosis, carry a risk of bleeding. We only found two small trials involving 79 patients; the results of the review suggested that anticoagulant drugs are probably safe and may be beneficial for people with sinus thrombosis but these results are not conclusive. 


\section{B A C K G R O U N D}

Cerebral venous sinus thrombosis (CVST) is a rare condition, with a highly variable clinical presentation and prognosis. The estimated incidence is about 2 to 4 per million people per year. A study in children less than 18 years old found a higher incidence of 6.7 per million per year (deVeber 2001). Symptoms and signs include headache, focal or generalised seizures, and neurologic deficits or coma (Bousser 2007; Stam 2005). Intracranial pressure is often elevated due to a diminished absorption of cerebrospinal fluid. This may cause papilloedema and, rarely, visual impairment. Obstruction of the venous drainage may cause local cerebral oedema and venous infarcts, which occur in approximately half of all patients (Ferro 2004). Venous infarcts are often haemorrhagic and may transform into large and possibly lethal cerebral haemorrhages. On the other hand, many patients have a benign course, with mainly signs of increased intracranial pressure but without neurologic impairment.

Treatment of CVST with anticoagulants has been controversial. Anticoagulant drugs are expected to arrest the thrombotic process and may prevent thrombus propagation, new venous infarcts and neurologic deterioration in patients with CVST. In addition, anticoagulants may prevent pulmonary embolism that can occur in these patients (Diaz 1992). Anticoagulation may also promote intracerebral haemorrhages (ICH), by causing haemorrhagic transformation of venous infarcts, although welldocumented cases of such events are rare (Bousser 1997). In addition, anticoagulants always carry a risk of extracerebral haemorrhage (van Dongen 2004).

Several uncontrolled case series suggested that the neurological outcome after cerebral venous sinus thrombosis could be improved with heparin therapy, without an increase in haemorrhagic complications (Ameri 1992; Bousser 1985; Ferro 2001; Villringer 1994). One report described neurologic deterioration after anticoagulant treatment for sinus thrombosis in two patients (Gettelfinger 1977), but these examples have been criticised: one patient received urokinase in addition to heparin, and the other developed CVST while on prophylactic subcutaneous heparin (Bousser 1997). In a large case series from Portugal, new intracranial haemorrhages developed in four of the $112(3.6 \%)$ patients treated with anticoagulants, and in two of $30(6.7 \%)$ patients who did not receive anticoagulants (Ferro 2001). Einhaupl 1991 reported three new ICHs in an uncontrolled series of 56 patients (5.4\%) treated with dose-adjusted intravenous heparin. Nevertheless, both studies reported that outcome was better for patients treated with anticoagulants.

In the early 1990s the first small randomised trials were set up to resolve the above-mentioned therapeutic dilemma. This Cochrane Review aimed to combine the results of all randomised trials that compared anticoagulant treatment for CVST with control treatment without anticoagulants and that met pre-defined criteria.

\section{OB JECTIVES}

To review the best available evidence regarding the efficacy and safety of anticoagulant therapy in patients with CVST. We tested the following hypotheses among patients with confirmed CVST (thrombosis of at least one intracranial venous sinus or cerebral vein).
1. Treatment with therapeutic doses of unfractionated heparin, low-molecular-weight heparin, or coumarin(s) is associated with a reduced risk of being dead or dependent a few months after the onset of CVST.

2. Treatment with therapeutic doses of unfractionated heparin, low-molecular-weight heparin, or coumarin(s) is not associated with an increase in symptomatic intra-cranial or severe extracranial haemorrhages that may offset a treatment benefit.

\section{METHODS}

\section{Criteria for considering studies for this review}

\section{Types of studies}

We included all unconfounded randomised trials in which anticoagulant therapy was compared with placebo or open control in patients with confirmed CVST. In addition, we included studies that compared different anticoagulant regimens. We also sought open trials and non-blinded trials. If we found such trials, we planned to do sensitivity analyses, first including and then excluding them, to determine the effect on the results. We excluded trials in which allocation to treatment or control group was not truly random or where allocation was not adequately concealed.

\section{Types of participants}

We selected trials that included patients with thrombosis of one or more intracranial venous sinuses documented by magnetic resonance imaging (MRI), computed tomography (CT) venography, or conventional angiography. We included trials that included patients with CVST and intracranial haemorrhage documented prior to anticoagulant treatment. We excluded trials that included patients diagnosed by CT scan alone, without CT-venography.

\section{Types of interventions}

We included all randomised controlled trials that compared the effects of anticoagulant therapy with placebo or open control on neurological outcome and death in patients with CVST. This included all anticoagulant regimens that aimed at a therapeutic level of anticoagulation, such as parenteral therapy with unfractionated heparin, low-molecular-weight heparin, heparinoids, or oral therapy with coumarin(s), or combinations, for at least three days. We also included studies which compared different types of heparin. We excluded trials which tested lowdose prophylactic anticoagulant regimens, antiplatelet agents, thrombolytic therapy, or defibrinogenating agents.

\section{Types of outcome measures}

We extracted the following outcomes of interest for each treatment group.

\section{Primary outcome measures}

1. Death from any cause at the end of the scheduled trial follow-up.

2. Death or dependency (needing help with activities of daily living) at the end of the scheduled trial follow-up.

\section{Secondary outcome measures}

1. Pulmonary embolism (diagnosed during life or at autopsy) within the scheduled treatment or follow-up period.

2. Symptomatic fatal or non-fatal intracranial haemorrhage, defined as any new intracranial haemorrhage or haemorrhagic 
transformation of a cerebral infarct that developed after randomisation, that was documented by CT or MRI scanning, or at autopsy, and that caused clinically manifest neurologic deterioration.

3. Major extracranial haemorrhage, defined as any bleeding that required transfusion or significant surgical intervention, or that caused permanent disabling deficit (e.g. intra-ocular bleeding causing blindness).

\section{Search methods for identification of studies}

See the 'Specialized register' section in the Cochrane Stroke Group module.

We searched the Cochrane Stroke Group Trials Register, which was last searched by the Managing Editor on 6 August 2010. In addition, we searched MEDLINE (1950 to August 2010) (Appendix 1), EMBASE (1980 to August 2010) (Appendix 2) and the Cochrane Central Register of Controlled Trials (The Cochrane Library 2011, Issue 1) (Appendix 3). We developed the search strategies in collaboration with the Cochrane Stroke Group Trials Search Co-ordinator.

In an effort to identify further published, unpublished and ongoing trials we:

1. searched the following clinical trials registers (August 2010):

a. ClinicalTrials.gov (www.clinicaltrials.gov);

b. Stroke Trials Registry (www.strokecenter.org/trials/);

c. WHO International Clinical Trials Registry Platform (ICTRP) (http://www.who.int/ictrp/search/en/);

2. searched the bibliographies of all references chosen for full manuscript review;

3. contacted authors who have published review articles, books, large case series or clinical trials in this topic.

We searched for trials in all languages and arranged translation of relevant articles published in languages other than English and Dutch.

\section{Data collection and analysis}

The review authors reviewed all titles obtained by the method outlined above. We discarded references obviously not relevant to the review question (primary study population not CVST, case reports, small descriptive case series). Two review authors (SFTM de $\mathrm{B}, \mathrm{JS}$ ) independently reviewed the abstracts of the remaining studies to establish whether they met the minimum selection criteria. We included abstracts classified by both review authors as 'accepted', or 'unsure' for further review. Abstracts rated by only one reviewer as either 'accepted', or 'unsure' were reviewed a second time by both and discrepancies resolved by discussion. Both review authors independently evaluated the full articles of the remaining references. Each review author rated each study as 'accepted', 'unsure' or 'rejected' based on the selection criteria. Where insufficient information was available, we tried to approach the authors for additional information.

For articles accepted into the review, two reviewers (SFTM de B, JS) independently extracted outcomes for each of the two treatment groups (anticoagulant treatment and control). We included the outcome data for each patient in the treatment group to which the patient was originally allocated (intention-to-treat analysis). We calculated a weighted estimate of the treatment effects across trials (relative risk, absolute risk reduction) using RevMan 5.0 (RevMan 2008).

\section{RE S U L T S}

\section{Description of studies}

We identified a total of nine possibly relevant studies in the Cochrane Stroke Group Trials Register, 1717 references from the searches of MEDLINE and EMBASE and 103 references from the search of the Cochrane Central Register of Controlled Trials. From the results of these searches, we identified five potentially relevant studies (CVST Group 1999; Einhaupl 1991; Maiti 1997; Modi 2006; Nagaraja 1995). Four studies compared efficacy of heparin with control treatment (CVST Group 1999; Einhaupl 1991; Maiti 1997; Nagaraja 1995) and one study compared unfractionated heparin with low-molecular-weight heparin (Modi 2006). We did not find any studies that included paediatric patients and we did not identify any ongoing studies in the clinical trial registries.

\section{Trials fulfilling the inclusion criteria}

Einhaupl 1991 performed the first clinical trial of heparin in adult CVST patients. Sixty patients were planned to be included in a single centre trial (Germany), which was stopped after the inclusion of 20 patients (planned interim analysis). The diagnosis of CVST was made by intra-arterial contrast angiography. Patients with the usual contraindications for heparin were excluded. Treatment consisted of intravenous high-dose unfractionated heparin, 25,000 to 65,000 IU/day, after a bolus of $3000 \mathrm{IU}$, or placebo (saline infusion). The heparin dose was adjusted to obtain a partial thromboplastin time (PTT) value of at least twice the pre-treatment value, and maximally 120 seconds. The treating physician was not blinded but the patients and the physicians who assessed the outcomes were. The primary outcome was the clinical condition at three months after randomisation, assessed with a composite CVST severity scale, with items for headache, focal signs, seizures, and level of consciousness. Intracranial haemorrhage (ICH), diagnosed by one of two routine CT scans, was the secondary endpoint. After 10 patients in each treatment group were included the study was stopped because a statistically significant effect in favour of heparin was found, based upon scores on the CVST severity scale. Patients in both treatment groups were balanced for baseline variables, except with regard to the duration from onset of symptoms to the start of treatment, which was 33 days in the heparin group and 25 days in the placebo group.

In the placebo group, three patients died, six survived with a minor deficit and one recovered completely. In the heparin group, two patients had minor deficits and eight recovered completely. According to the CVST severity scale patients with a minor deficit may have slight to severe headaches, transient to mild paresis, or seizures. For the meta-analysis we considered all surviving patients with a minor deficit at three months as good outcomes (independent). There were two patients with new $\mathrm{ICHs}$ in the control group, and none in the heparin group. It is not clear whether these ICHs were symptomatic or only detected on the follow-up CT scans.

CVST Group 1999 included 60 adult patients in a multi-centre trial in the Netherlands and in the UK. The diagnosis of CVST was made by intra-arterial contrast angiography or by MRI and MR angiography. Patients with the usual contraindications, including recent lumbar 
puncture for heparin, were excluded. Treatment consisted of subcutaneous low-molecular-weight heparin (nadroparin) in a dose of 180 anti-factor $\mathrm{Xa} \mathrm{U} / \mathrm{kg} / 24$ hour or placebo, administered by two subcutaneous injections daily for three weeks. Patients, treating physicians, and assessors were blinded during the first three weeks. Patients allocated to nadroparin received followup treatment with warfarin (non-blinded) for 10 weeks (total duration of anticoagulant treatment 13 weeks). Primary outcomes were scores on the Barthel index (activities of daily living), and on a stroke handicap scale (The Oxford handicap scale), and death. Secondary endpoints were symptomatic $\mathrm{ICH}$ and severe extracranial haemorrhage. Assessments were done at three weeks (blind), and at 12 weeks (non-blinded). Sixty patients were randomised ( 30 in each treatment group). Patients in both treatment groups were balanced for baseline variables, except for isolated intracranial hypertension and CT/MRI infarcts (see below). One patient from the placebo group was withdrawn after randomisation (wrong diagnosis: arterial cerebral infarction). He was independent after three and 12 weeks.

After 12 weeks four of the 30 participants (13\%) in the nadroparin group had a poor outcome, defined as death or dependence (Oxford handicap score 3 to 5). In the placebo group six of the 29 participants $(21 \%)$ had a poor outcome. The open assessment showed essentially similar results to the blind assessment and is used in our meta-analysis. There were no symptomatic intracranial haemorrhagic complications. One patient in the nadroparin group had a major non-fatal gastrointestinal haemorrhage.

\section{Excluded studies}

A study from India randomised 57 women with puerperal CVST (Nagaraja 1995). We excluded this study because the diagnosis was not confirmed by our pre-defined criteria (angiography, MRI/ MRA or CT-venography) but by CT only. Patients with signs of cerebral haemorrhage on CT were excluded. Patients were initially treated with intravenous unfractionated heparin, $5000 \mathrm{IU}$ every six hours, and then dose-adjusted to reach a PTT of 1.5 times the initial value. Details of the randomisation procedure, allocation concealment, and pre-defined outcome measures were not given in the published article. Assessment was non-blinded. Twenty-nine patients received heparin and 28 were controls. Two patients in the control group died, and one had a residual paresis at six months. In the heparin group all patients recovered.

A second study from India reported a randomised controlled trial of 40 patients ( 20 heparin, 20 placebo). This study has been published as an abstract only (Maiti 1997). According to the abstract, mortality was $15 \%$ in the heparin group and $40 \%$ in the placebo group. Details of diagnostic confirmation, the randomisation procedure, allocation concealment, and pre-defined outcome measures have not been published. In a personal communication, however, the lead author reported that CVT was not diagnosed by angiography, $\mathrm{MRI} / \mathrm{MRA}$ or CT-venography in all patients. No placebo was given to the control group and the physicians were not blinded to the treatment allocation. Because of these methodological limitations and the fact that the full results have not been published in a peerreviewed journal, we excluded the study from the analysis.

\section{Studies awaiting classification}

We also identified a single randomised controlled trial which compares unfractionated heparin with low-molecular-weight heparin in CVST (Modi 2006). The results of this study have been published as an abstract only. A total of 75 patients were randomised and there was no difference in clinical outcome between the groups at 90 days. Details of diagnostic confirmation, the randomisation procedure, allocation concealment, and outcome measures are not yet available. In a personal communication, one of the principal investigators has indicated that the complete results will be submitted to a peerreviewed journal.

\section{Risk of bias in included studies}

CVST Group 1999 recruited patients from 15 hospitals in the Netherlands and the UK. Treatment allocation was concealed by using numbered packages containing prefilled syringes with nadroparin or identically appearing placebo. A computer program randomly allocated one of the numbered packages to each patient, according to a stratified block randomisation schedule, with strata for ICH on the pretreatment CT scan, and for chronic intracranial hypertension. A minimisation procedure was applied to allocate approximately equal amounts of control and placebo patients to the strata. An error in the randomisation program caused temporary imbalance, which was corrected during the second half of the trial. Patients and doctors were blinded during the first three weeks of placebo-controlled treatment and at the first assessment at three weeks. The success of blinding was not examined. Followup treatment and assessment at 12 weeks were non-blinded. One patient (on placebo) with a wrong diagnosis was withdrawn after randomisation. No patients were lost to follow-up. Baseline data were balanced (age, sex, treatment delay, number with Glasgow Coma Score $<8$, seizures, focal deficits, number with $\mathrm{ICH}$ ), except isolated intracranial hypertension (more in the placebo group) and infarcts on CT/MRI (more in the nadroparin group). Both factors were not significantly associated with outcome in univariate and multiple logistic regression analysis (de Bruijn 2001).

Einhaupl 1991 was a single centre study, performed in a large teaching hospital in Munich, Germany. Treatment allocation was concealed by using numbered sealed envelopes. Random assignment was done by a computer random number generator. The patients and the assessing physician were blinded. The treating physician who adjusted the heparin dosage was non-blinded. Placebo consisted of continuous saline infusion. The success of blinding was not examined. There were no withdrawals after randomisation and no patients lost to follow-up. All patients were included in the analysis. Baseline data were balanced (age, sex, Glasgow Coma Score, CVST severity scale, number with ICH), except for treatment delay.

\section{Effects of interventions}

We presented results as relative risks with $95 \% \mathrm{Cl}$ and as absolute risk differences or absolute risk reductions (ARR). Odds ratios are also provided.

\section{Primary outcome measures}

\section{Death from any cause at the end of the scheduled trial follow-up}

Anticoagulant treatment was associated with a relative risk of death of $0.33(95 \% \mathrm{Cl} 0.08$ to 1.21$)$ (Analysis 1.1). The absolute reduction in the risk of death was $-13 \%(95 \% \mathrm{Cl}-27 \%$ to $1 \%)$ 
Death or dependency at the end of the scheduled trial follow-up period

In both trials, anticoagulant treatment was associated with a non-significantly reduced number of patients who were dead or dependent three months after the diagnosis of CVST. Einhaupl 1991 did not formally assess dependency. Three (out of 10) patients died in the control group, and none died in the heparin group. All patients treated with heparin recovered fully, one with mild residual symptoms. One of the seven surviving patients in the control group had a CVST severity score of 3 , indicating severe headache or mild paresis. The others had better outcomes. We classified all surviving patients in the control group as independent. In CVST Group 1999 four of the 30 patients treated with nadroparin were dead (two patients) or dependent (two patients) after three months. In the control group there were four deaths and two patients were dependent. Meta-analysis showed a non-significant relative risk of $0.46(95 \% \mathrm{Cl} 0.16$ to 1.31$)$ in death or dependency associated with anticoagulant therapy (Analysis 1.2). The absolute reduction in the risk of death or dependency at follow-up was - $13 \%$ (95\% $\mathrm{Cl}-30 \%$ to $3 \%)$.

\section{Intention-to-treat analysis}

One patient in the placebo group of CVST Group 1999 had an incorrect diagnosis (arterial ischaemic stroke). When the data from this patient were included in a full intention-to-treat analysis, the effect estimates for both primary outcomes did not materially change, nor did the overall conclusions.

\section{Secondary outcome measures}

\section{Confirmed pulmonary embolism}

There were no cases of confirmed pulmonary embolism. However, both trials each reported one patient in the placebo group with unconfirmed but probable pulmonary embolism. In Einhaupl 1991 one patient had severe pulmonary infarction, but details of diagnostic confirmation were not available. In CVST Group 1999 one patient suddenly died after initial recovery, presumably due to massive pulmonary embolism. Autopsy was not performed.

\section{Symptomatic intracranial haemorrhage (ICH)}

In both trials, no new symptomatic ICHs were diagnosed after initiation of anticoagulant therapy, despite the fact that many patients who received heparin had some degree of $\mathrm{ICH}$ on their pre-treatment CT scans (three of 10 patients in Einhaupl 1991; 15 of 30 patients in CVST Group 1999). Einhaupl 1991 reported two patients in the control group with new ICHs but without clinical details. Since this study performed at least two routine CT scans in each patient, we classified these haemorrhages as asymptomatic.

\section{Major extracranial haemorrhage}

One patient on nadroparin treatment in CVST Group 1999 suffered a major non-fatal gastrointestinal haemorrhage. This amounts to a pooled relative risk of $2.9(\mathrm{Cl} 0.12$ to 68.5$)$ and an absolute risk difference of $2 \%(95 \% \mathrm{Cl}-6$ to 11$)$.

\section{Sensitivity analysis}

Since the data from the included studies were so sparse we performed a post-hoc sensitivity analysis including the data from the excluded trials (Maiti 1997; Nagaraja 1995). If we included these data, then the pooled relative risk for death would be 0.33 (95\%
$\mathrm{Cl} 0.14$ to 0.78 ). There were insufficient data to allow sensitivity analysis for death or dependency.

\section{DISCUSSION}

\section{Efficacy of anticoagulant treatment}

The two small trials which met our predefined inclusion criteria showed a non-significant trend towards fewer deaths or dependency in patients treated with anticoagulants. However, the confidence intervals included no effect and the combined evidence failed to reach conventional statistical significance.

We excluded two other studies from the analysis (Maiti 1997; Nagaraja 1995). Maiti 1997 has only been published as an abstract and important details about the study design were not available. Nagaraja 1995 did not meet our predefined criterion: CVST was not diagnosed by angiography, MRI/MRA, or CT-venography. Nevertheless, it seems likely that most of these women had (puerperal) CVST. Interestingly, the small beneficial effect of heparin seen in the included trials was also observed in this study: two of the 28 controls died and no deaths occurred in the 29 patients treated with heparin. Therefore, these results provide some support to the efficacy of heparin in CVST.

The validity of meta-analysis of the two included studies might be questioned because different kinds of heparin were used (Benamer 2000). Einhaupl 1991 used unfractionated, intravenous, dose-adjusted heparin; CVST Group 1999 used subcutaneous, fixed dose, low-molecular-weight heparin (nadroparin). A Cochrane Review of 22 randomised trials among patients with leg-vein thrombosis showed a better efficacy and fewer haemorrhages of low-molecular-weight heparin compared with unfractionated heparin (van Dongen 2004). A recent post-hoc analysis of a large prospective cohort study of CVST suggested that lowmolecular-weight heparin also leads to better outcomes and fewer haemorrhagic complications than unfractionated heparin in these patients (Coutinho 2010). In addition, results of a small randomised study which directly compared low-molecular-weight heparin with unfractionated heparin for CVST have been published as an abstract (Modi 2006). This study of 75 patients did not show any major differences in efficacy but final results have not yet been published. In summary, the differences in efficacy between lowmolecular-weight heparin and unfractionated heparin, although significant in leg-vein thrombosis, are probably not very large, and combining both CVST trials seems justified as far as treatment is concerned.

A second problem is the difference in the timing of treatment. The average time from initial symptoms to treatment was about four weeks in Einhaupl 1991: 32 days in the heparin group, 25 days in the controls. In CVST Group 1999 treatment started after an average of 10 days in the nadroparin group and 11 days in the control group. Some diagnostic delay in CVST is usual. In two non-randomised cohort studies, average delays of four and seven days were reported (Ferro 2001; Ferro 2004). The diagnosis can be difficult due to the variable and often non-specific symptoms. In addition, the diagnosis was more difficult before the advent of MRI. The long therapeutic delay in Einhaupl 1991 may be caused by a diagnostic delay, although even with intra-arterial angiography a delay of four weeks from onset of symptoms to the start of treatment seems exceptionally long. This delay could also indicate that a subgroup of patients with more prolonged course was recruited, for instance 
patients who deteriorated after an initial favourable course without anticoagulant treatment.

\section{Pulmonary embolism}

One of our predefined outcomes was pulmonary embolism (PE). Two cases of clinically diagnosed PE occurred in the placebo groups, but data on diagnostic confirmation were not available. These cases point to a potential benefit of anticoagulants in CVST. Pulmonary embolism is not rare in CVST and might be caused by embolism from a thrombosed sinus or from simultaneous leg-vein thrombosis (Diaz 1992). The latter is not unlikely: many patients with CVST are in a prothrombotic state and often immobilised. As in leg-vein thrombosis an important benefit of anticoagulant treatment in CVST might be the prevention of pulmonary embolism.

\section{Intracerebral haemorrhage}

The main reason for many clinicians avoiding anticoagulants in CVST was the fear of haemorrhagic complications, notably intracerebral bleeding. Many patients with CVST have cerebral haemorrhages or haemorrhagic infarcts at the time of the diagnosis, before treatment (25\% in Einhaupl 1991; $49 \%$ in CVST Group 1999). Yet, few cases of CVST with haemorrhagic deterioration after heparin have been published. In one study of seven patients two new intracerebral haemorrhages developed after anticoagulant treatment (Gettelfinger 1977). One patient received urokinase in addition to heparin and the other developed CVST while on prophylactic subcutaneous heparin (Bousser 1997). In two published case series treated with heparin no new intracerebral haemorrhages occurred (Ameri 1992; Bruckner 1998), but in two other uncontrolled series intracerebral haemorrhage did occur in 3.6\% (Ferro 2001) and 5.4\% (Einhaupl 1991) of the anticoagulated patients. In the International Study on Cerebral Vein and dural sinus Thrombosis (ISCVT), the largest prospective cohort study on CVST, new intracerebral haemorrhages occurred in 33 of 520 patients $(6 \%)$ who were treated with heparin in therapeutic dose (Ferro 2004; Girot 2007). However, this study was not designed to assess new intracerebral haemorrhages after heparin therapy, and follow-up brain imaging was not performed in all patients. In the two trials included in this review no symptomatic intracerebral haemorrhages occurred after anticoagulant therapy in 40 patients. This suggests that the risk of intracerebral haemorrhage in patients with sinus thrombosis who are treated with anticoagulants is low. However, $0 \%$ symptomatic intracerebral haemorrhages in 40 patients treated with (low-molecular-weight) heparin is associated with a $95 \%$ confidence interval of $0 \%$ to $9 \%$, thus an incidence of up to $9 \%$ new intracerebral haemorrhages cannot be excluded.

\section{Extracerebral haemorrhage}

One major extracerebral haemorrhage occurred in a patient treated with low-molecular-weight heparin in CVST Group 1999. This rate $(3.3 \%)$ is within the range to be expected in any group of patients treated with heparin. In a Cochrane Review of 22 trials assessing heparin for leg-vein thrombosis, unfractionated heparin was associated with $2.1 \%$ major haemorrhages and low-molecularweight heparin with $1.0 \%$ (van Dongen 2004).

\section{Sensitivity analysis}

Our post-hoc sensitivity analysis, including the data from the two trials which did not meet our eligibility criteria (Maiti 1997; Nagaraja
1995), were of interest but must be interpreted with great caution since they are potentially subject to bias. However, the effects observed were consistent with those from the included studies and provide limited additional support for our carefully worded conclusions.

\section{Anticoagulation in paediatric patients}

We did not identify any randomised trial that included paediatric patients and data on the safety of heparin in children from other studies are limited (deVeber 2001). As a result, it was not possible to provide an evidence-based recommendation from randomised trials on the use of anticoagulation in these patients. International guidelines tentatively recommend the use of anticoagulation in older children and in selected neonates (Monagle 2008: Roach 2008; Saposnik 2011) and heparin is being increasingly used in paediatric patients (deVeber 2001; Vieira 2010). A recent post-hoc analysis of a prospective cohort study of 162 paediatric cases of CVST showed that protocol-based anticoagulant treatment (heparin, enoxaparin and warfarin) was associated with a significant reduction in thrombus propagation (Moharir 2010) and was associated with new or increased bleeding in 6\%, all non-fatal bleeds. Propagation was significant in that it was associated with new venous infarcts in $10 \%$ of neonates and $40 \%$ of children and with worse clinical outcome in children $(P=0.053)$. While these data provide some support for the use of anticoagulation in children, a randomised trial seems warranted, especially in neonates.

\section{AUTHORS' CONCLUSIONS}

\section{Implications for practice}

Anticoagulant treatment in patients with cerebral venous sinus thrombosis appears to be safe and is associated with an apparent reduction in the risk of death or dependency which did not reach statistical significance. In the absence of more information from randomised trials clinicians will need to base their treatment decisions on the limited information available.

\section{Implications for research}

Although the estimated pooled risk reductions did not reach statistical significance, patients and doctors may be reluctant to embark upon a new trial in adult patients that includes a placebo group. International guidelines recommend the use of heparin as the primary treatment of patients with CVST, regardless of the presence of baseline intracerebral haemorrhagic lesions (Einhaupl 2010; Saposnik 2011), and most physicians follow this recommendation (Ferro 2004). In paediatric patients, especially neonates, a randomised trial seems warranted.

Large consecutive cohort studies have helped to identify subgroups of patients with a poor prognosis (Ferro 2004). In such patients randomised trials testing more aggressive, and probably more hazardous, therapies such as local (direct) thrombolysis or thrombosuction, are justified and needed.

\section{ACKNOWLEDGEMENTS}

We would like to thank Prof Peter Sandercock for his support and stimulating discussions. 


\section{R E F E R E N C E S}

\section{References to studies included in this review \\ CVST Group 1999 \{published data only\}}

de Bruijn SFTM, Stam J, for the Cerebral Venous Sinus Thrombosis Study Group. Randomised, placebo-controlled trial of anticoagulant treatment with low-molecular weight heparin for cerebral sinus thrombosis. Stroke 1999;30:484-8.

\section{Einhaupl 1991 \{published data only\}}

Einhaupl KM, Villringer A, Meister W, Mehraein S, Garner C, Pellkopfer M, et al. Heparin treatment in sinus venous thrombosis. Lancet 1991;338:597-600.

\section{References to studies excluded from this review \\ Maiti 1997 \{published data only\}}

Maiti B, Chakrabarti I. Study on cerebral venous thrombosis with special reference to efficacy of heparin. Journal of the Neurological Sciences 1997;150 Suppl:S147.

\section{Nagaraja 1995 \{published data only\}}

Nagaraja D, Rao BSS, Taly AB, Subhash MN. Randomized controlled trial of heparin in puerperal cerebral venous/sinus thrombosis. Nimhans Journal 1995;13(2):111-5.

\section{References to studies awaiting assessment}

\section{Modi 2006 \{published data only\}}

Modi M, Prabhakar S, Pandey AK, Khurana D, Lal V, Das CP, et al. A study of comparison of unfractionated vs low molecular weight heparin in cerebral venous thrombosis. International Journal of Stroke 2006;1 Suppl 1:40.

\section{Additional references}

\section{Ameri 1992}

Ameri A, Bousser MG. Cerebral venous thrombosis. Neurologic Clinics 1992;10:87-111.

\section{Benamer 2000}

Benamer HT, Bone I. Cerebral venous thrombosis: anticoagulants or thrombolytic therapy?. Journal of Neurology, Neurosurgery and Psychiatry 2000;69:427-30.

\section{Bousser 1985}

Bousser MG, Chiras J, Sauron B, Castaigne P. Cerebral venous thrombosis. A review of 38 cases. Stroke 1985;16:199-213.

\section{Bousser 1997}

Bousser MG, Ross Russell R. Cerebral venous thrombosis. In: Warlow CP, Van Gijn J editor(s). Major Problems in Neurology. Vol. 33, London, UK: WB Saunders, 1997.

\section{Bousser 2007}

Bousser MG, Ferro JM. Cerebral venous thrombosis: an update. Lancet Neurology 2007;6(2):162-70. [PUBMED: 17239803]

\section{Bruckner 1998}

Bruckner AB, Vollert-Rogenhofer H, Wagner M, Stieglbauer K, Felber S, Trenkler J, et al. Heparin treatment in acute cerebral sinus venous thrombosis. Cerebrovascular Diseases 1998;8:331-7.

\section{Coutinho 2010}

Coutinho JM, Ferro JM, Canhao P, Barinagarrementeria F, Bousser MG, Stam J. Unfractionated or low-molecular weight heparin for the treatment of cerebral venous thrombosis. Stroke 2010;41(11):2575-80. [PUBMED: 20930161]

\section{de Bruijn 2001}

De Bruijn SFTM, de Haan RJ, Stam J, for the Cerebral Venous Sinus Thrombosis Study Group. Clinical features and prognostic factors of cerebral sinus thrombosis in a prospective series of 59 patients. Journal of Neurology, Neurosurgery and Psychiatry 2001;70:105-8

\section{deVeber 2001}

deVeber G, Andrew M, Adams C, Bjornson B, Booth F, Buckley DJ, for the Canadian Pediatric Stroke Study Group. Cerebral sinovenous thrombosis in children. New England Journal of Medicine 2001;345:417-23.

\section{Diaz 1992}

Diaz JM, Schiffman JS, Urban ES, Maccario M. Superior sagittal sinus thrombosis and pulmonary embolism: a syndrome rediscovered. Acta Neurologica Scandinavica 1992;86:390-6.

\section{Einhaupl 2010}

Einhaupl K, Stam J, Bousser MG, De Bruijn SF, Ferro JM, Martinelli I, et al. EFNS guideline on the treatment of cerebral venous and sinus thrombosis in adult patients. European Journal of Neurology 2010;17(10):1229-35. [PUBMED: 20402748]

\section{Ferro 2001}

Ferro JM, Correia M, Pontes C, Baptista MV, Pita F, for the Cerebral Venous Thrombosis Portuguese Collaborative Study Group (Venoport). Cerebral vein and dural sinus thrombosis in Portugal: 1980-1998. Cerebrovascular Diseases 2001;11:177-82.

\section{Ferro 2004}

Ferro JM, Canhao P, Stam J, Bousser MG, Barinagarrementeria F. Prognosis of cerebral vein and dural sinus thrombosis: results of the International Study on Cerebral Vein and Dural Sinus Thrombosis (ISCVT). Stroke 2004;35(3):664-70. [PUBMED: 14976332]

\section{Gettelfinger 1977}

Gettelfinger DM, Kokmen E. Superior sagittal sinus thrombosis. Archives of Neurology 1977;32:2-6.

\section{Girot 2007}

Girot M, Ferro JM, Canhao P, Stam J, Bousser MG, Barinagarrementeria $\mathrm{F}$, et al. Predictors of outcome in patients with cerebral venous thrombosis and intracerebral hemorrhage. Stroke 2007;38(2):337-42. [PUBMED: 17204682] 


\section{Moharir 2010}

Moharir MD, Shroff M, Stephens D, Pontigon AM, Chan A, MacGregor $\mathrm{D}$, et al. Anticoagulants in pediatric cerebral sinovenous thrombosis: a safety and outcome study. Annals of Neurology 2010;67(5):590-9. [PUBMED: 20437556]

\section{Monagle 2008}

Monagle P, Chalmers E, Chan A, DeVeber G, Kirkham F, Massicotte $P$, et al. Antithrombotic therapy in neonates and children: American College of Chest Physicians EvidenceBased Clinical Practice Guidelines (8th Edition). Chest 2008;133:887S-968S.

\section{RevMan 2008 [Computer program]}

The Nordic Cochrane Centre, The Cochrane Collaboration. Review Manager (RevMan). Version 5.0. Copenhagen: The Nordic Cochrane Centre, The Cochrane Collaboration, 2008.

\section{Roach 2008}

Roach ES, Golomb MR, Adams R, Biller J, Daniels S, Deveber G, et al. Management of stroke in infants and children: a scientific statement from a Special Writing Group of the American Heart Association Stroke Council and the Council on Cardiovascular Disease in the Young. Stroke 2008;39(9):2644-91. [PUBMED: 18635845]

\section{Saposnik 2011}

Saposnik G, Barinagarrementeria F, Brown RD Jr, Bushnell CD, Cucchiara B, Cushman M, et al. Diagnosis and management of cerebral venous thrombosis: a statement for healthcare professionals from the American Heart Association/American Stroke Association. Stroke 2011;42(4):1158-92.

\section{Stam 2005}

Stam J. Thrombosis of the cerebral veins and sinuses. New England Journal of Medicine 2005;352(17):1791-8. [PUBMED: 15858188]

\section{van Dongen 2004}

van Dongen $\mathrm{CJ}$, van den Belt AG, Prins MH, Lensing AW. Fixed dose subcutaneous low molecular weight heparins versus adjusted dose unfractionated heparin for venous thromboembolism. Cochrane Database of Systematic Reviews 2004, Issue 4. [DOI: 10.1002/14651858.CD001100]

\section{Vieira 2010}

Vieira JP, Luis C, Monteiro JP, Temudo T, Campos MM, Quintas S, et al. Cerebral sinovenous thrombosis in children: clinical presentation and extension, localization and recanalization of thrombosis. European Journal of Paediatric Neurology 2010;14(1):80-5. [PUBMED: 19201633]

\section{Villringer 1994}

Villringer A, Bousser MG, Einhaupl KM. Cerebral sinus venous thrombosis. In: Hacke W editor(s). Neurocritical Care. Vol. 1, Berlin: Springer Verlag, 1994:654-60.

\section{CHARACTERISTICS OF STUDIES}

\section{Characteristics of included studies [ordered by year of study]}

Einhaupl 1991

\begin{tabular}{|c|c|}
\hline Methods & $\begin{array}{l}\text { Single centre placebo controlled trial } \\
\text { Concealment by sealed envelopes } \\
\text { Patient and assessor blind, doctor non-blind } \\
\text { Exclusions during trial: none } \\
\text { Losses to follow-up: none }\end{array}$ \\
\hline Participants & $\begin{array}{l}\text { Germany, } 20 \text { patients; } 55 \% \text { female. } \\
\text { Age }<10 \text { years old excluded } \\
\text { Mean ages } 36.3 \text { years (heparin) and } 37.2 \text { years (placebo) } \\
\text { CVST confirmed by angiography } \\
5 \text { patients with ICH before treatment }\end{array}$ \\
\hline Interventions & $\begin{array}{l}\text { Heparin iv bolus } 3000 \mathrm{IU} \text {, then } 25,000 \text { to } 65,000 \mathrm{IU} / \text { day, guided by PTT } \\
\text { Start of treatment mean } 32.5 \text { days (heparin) or } 24.8 \text { days (placebo) after first symptoms }\end{array}$ \\
\hline Outcomes & $\begin{array}{l}\text { Death and 10-point CVST severity scale at } 3 \text { months } \\
\text { ICH (by } 2 \text { follow-up CT scans) }\end{array}$ \\
\hline Notes & Study terminated after 20 patients because of a significant difference in CVST severity score \\
\hline \multicolumn{2}{|l|}{ Risk of bias } \\
\hline Bias & Authors' judgement Support for judgement \\
\hline
\end{tabular}


Einhaupl 1991 (Continued)
Allocation concealment
Low risk
A - Adequate
(selection bias)

\section{CVST Group 1999}

Multicentre placebo controlled trial
Concealment by central randomisation (computer program): stratified randomisation (minimisation)
and small block size to obtain balanced baseline characteristics
Patient, treating physician and assessor blind during 3 weeks, then open
Exclusions during trial: 1 (wrong diagnosis)
Losses to follow-up: none

\begin{tabular}{ll}
\hline Participants & Netherlands and UK, 59 patients; $85 \%$ female \\
Age $<18$ years old excluded \\
Mean ages 37.2 years (nadroparin) and 36.7 years (placebo) \\
CVST confirmed by angiography, or MRI/MRA \\
29 patients with ICH before treatment.
\end{tabular}

\begin{tabular}{|c|c|}
\hline Interventions & $\begin{array}{l}\text { Nadroparin } 2 \text { subcutaneous injections/24 hour } \\
\text { Total } 180 \text { anti-factor } \mathrm{Xa} \mathrm{U} / \mathrm{kg} / 24 \text { hour } \\
\text { Start of treatment mean } 10.0 \text { days (nadroparin) or } 11.3 \text { days (placebo) after first symptom }\end{array}$ \\
\hline Outcomes & $\begin{array}{l}\text { Barthel index, Oxford handicap score, and death at } 3 \text { weeks (blind) and } 3 \text { months (open) } \\
\text { Symptomatic new ICH (confirmed by CT scan) } \\
\text { Bleeding complications } \\
\text { Confirmed leg and pulmonary thromboembolism }\end{array}$ \\
\hline
\end{tabular}

\begin{tabular}{ll}
\hline Notes & First outcome assessment after 3 weeks (blind), second after 3 months (open) \\
& Temporary imbalance in allocation due to error in randomisation program
\end{tabular}

\section{Risk of bias}

\begin{tabular}{lll}
\hline Bias & Authors' judgement & Support for judgement \\
\hline $\begin{array}{l}\text { Allocation concealment } \\
\text { (selection bias) }\end{array}$ & Low risk & A - Adequate \\
\hline
\end{tabular}

CT: computed tomography brain scan

CVST: cerebral venous sinus thrombosis

$\mathrm{ICH}$ : intracerebral haematoma

iv: intravenous

MRA: magnetic resonance angiography

MRI: magnetic resonance imaging

PTT: partial thromboplastin time

Characteristics of excluded studies [ordered by study ID]

\begin{tabular}{ll}
\hline Study & Reason for exclusion \\
\hline Maiti 1997 & $\begin{array}{l}\text { Details of diagnostic confirmation, randomisation procedure, allocation concealment and pre-de- } \\
\text { fined outcome measures not published. Study published as an abstract only. Diagnosis not con- } \\
\text { firmed by angiography, MRI/MRA or CT-venography in all patients. }\end{array}$ \\
\hline Nagaraja 1995 & Diagnosis confirmed by unenhanced CT, not by angiography, MRI/MRA or CT-venography. \\
\hline \hline
\end{tabular}


$\mathrm{CT}$ : computed tomography brain scan MRA: magnetic resonance angiogram MRI: magnetic resonance imaging

Characteristics of studies awaiting assessment [ordered by study ID]

Modi 2006

\begin{tabular}{ll}
\hline Methods & Randomised trial \\
\hline Participants & Adult CVST patients \\
\hline Interventions & Unfractionated heparin versus low-molecular-weight heparin \\
\hline Outcomes & Not enough information \\
\hline Notes & Published as an abstract only. Awaiting full results \\
\hline
\end{tabular}

CVST: cerebral venous sinus thrombosis

DATA AND ANALYSES

Comparison 1. Overall benefit or harm of (LMW) heparin

\begin{tabular}{lllll}
\hline Outcome or subgroup title & $\begin{array}{l}\text { No. of } \\
\text { studies }\end{array}$ & $\begin{array}{l}\text { No. of par- } \\
\text { ticipants }\end{array}$ & Statistical method & Effect size \\
\hline 1 Death & 2 & 79 & Risk Ratio (M-H, Fixed, 95\% Cl) & $0.33[0.08,1.28]$ \\
\hline 2 Death or dependency & 2 & 79 & Risk Ratio (M-H, Fixed, 95\% Cl) & $0.46[0.16,1.31]$ \\
\hline
\end{tabular}

Analysis 1.1. Comparison 1 Overall benefit or harm of (LMW) heparin, Outcome 1 Death.

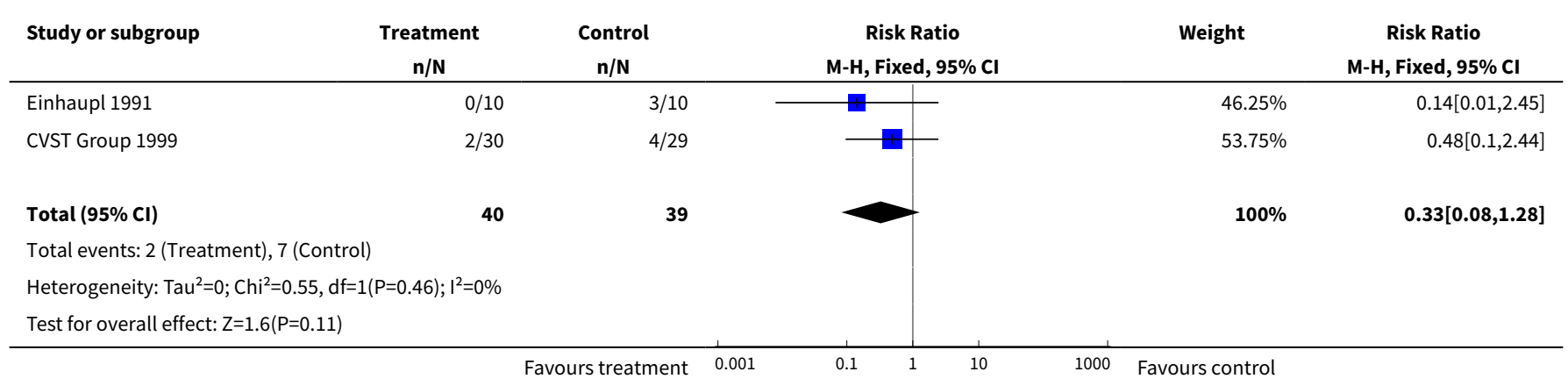


Analysis 1.2. Comparison 1 Overall benefit or harm of (LMW) heparin, Outcome 2 Death or dependency.

\begin{tabular}{|c|c|c|c|c|c|}
\hline Study or subgroup & $\begin{array}{c}\text { Treatment } \\
\mathrm{n} / \mathrm{N}\end{array}$ & $\begin{array}{c}\text { Control } \\
n / N\end{array}$ & $\begin{array}{c}\text { Risk Ratio } \\
\text { M-H, Fixed, 95\% Cl }\end{array}$ & Weight & $\begin{array}{c}\text { Risk Ratio } \\
\text { M-H, Fixed, } 95 \% \mathrm{Cl}\end{array}$ \\
\hline Einhaupl 1991 & $0 / 10$ & $3 / 10$ & $\longrightarrow$ & $36.45 \%$ & $0.14[0.01,2.45]$ \\
\hline CVST Group 1999 & $4 / 30$ & $6 / 29$ & & $63.55 \%$ & $0.64[0.2,2.05]$ \\
\hline Total $(95 \% \mathrm{Cl})$ & 40 & 39 & & $100 \%$ & $0.46[0.16,1.31]$ \\
\hline \multicolumn{6}{|c|}{ Total events: 4 (Treatment), 9 (Control) } \\
\hline Test for overall effect & & & & & \\
\hline
\end{tabular}

\section{Comparison 2. Haemorrhagic adverse events}

\begin{tabular}{lllll}
\hline Outcome or subgroup title & $\begin{array}{l}\text { No. of } \\
\text { studies }\end{array}$ & $\begin{array}{l}\text { No. of } \\
\text { partici- } \\
\text { pants }\end{array}$ & Statistical method & Effect size \\
\hline $\begin{array}{l}\text { 1 Symptomatic intracerebral haemorrhage } \\
\text { (new or increased) }\end{array}$ & 2 & 79 & Risk Ratio (M-H, Fixed, 95\% Cl) & $0.0[0.0,0.0]$ \\
\hline 2 Any severe haemorrhage & 2 & 79 & Risk Ratio (M-H, Fixed, 95\% Cl) & $2.90[0.12,68.50]$ \\
\hline
\end{tabular}

Analysis 2.1. Comparison 2 Haemorrhagic adverse events, Outcome 1 Symptomatic intracerebral haemorrhage (new or increased).

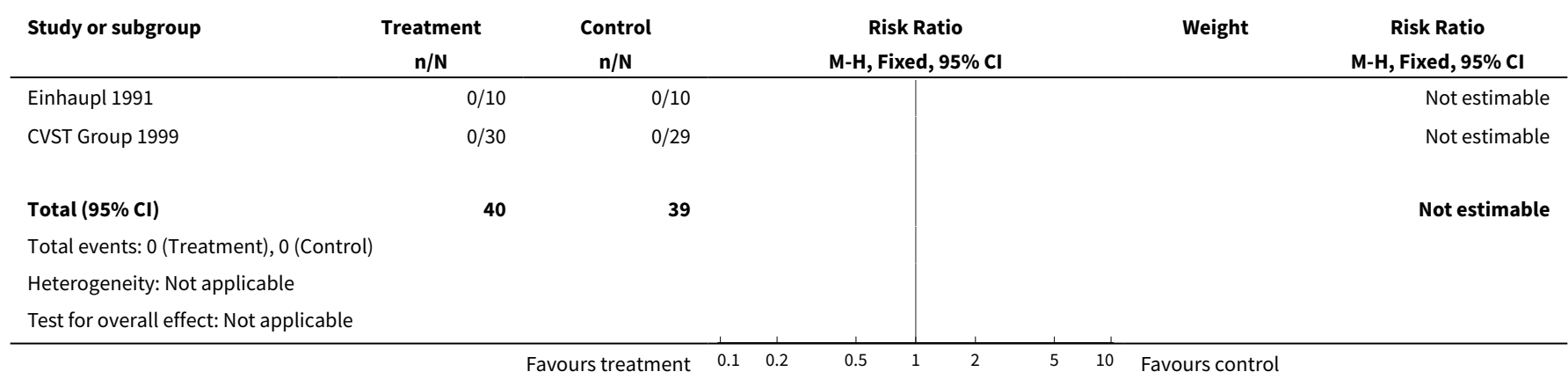

Analysis 2.2. Comparison 2 Haemorrhagic adverse events, Outcome 2 Any severe haemorrhage.

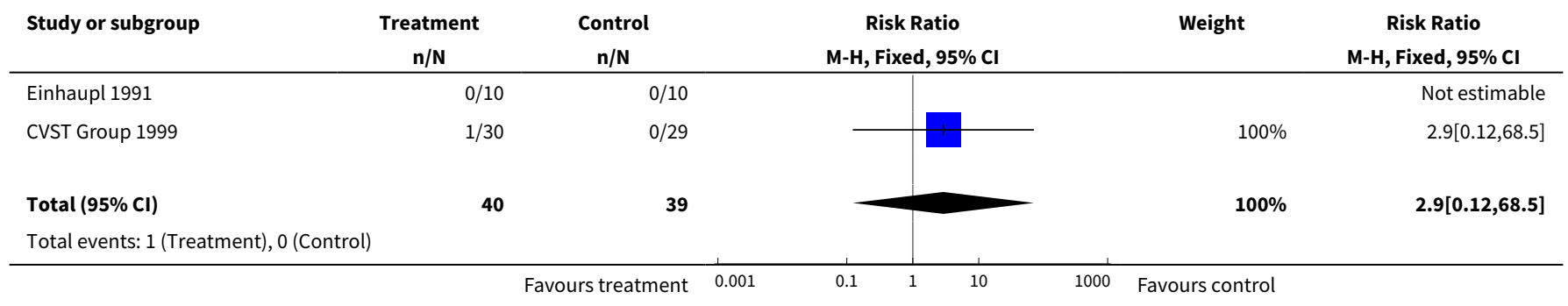




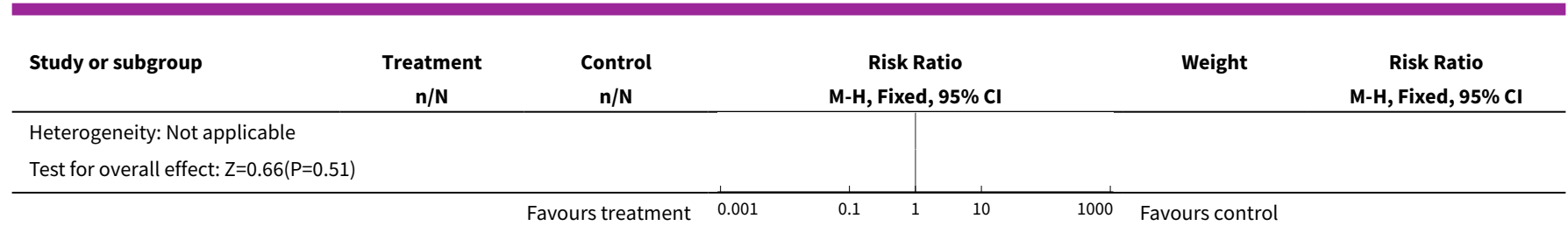

\section{APPENDICES}

\section{Appendix 1. MEDLINE search strategy}

We used the following search strategy for MEDLINE (Ovid) and adapted it to search the Cochrane Central Register of Controlled Trials.

1. "intracranial embolism and thrombosis"/ or intracranial thrombosis/ or exp sinus thrombosis, intracranial/

2. cerebral veins/ or exp cranial sinuses/

3. thrombosis/or venous thrombosis/

4. 2 and 3

5. (sinus\$ or sinovenous or cerebral venous or cerebral vein\$ or cavernous or sagittal venous or sagittal vein\$).tw.

6. thrombo\$.tw.

7. 5 and 6

8. 1 or 4 or 7

9. exp anticoagulants/

10.anticoagulant\$.tw.

11. (acenocoumarol\$ or apixaban or betrixaban or dabigatran or dicoumarol\$ or ethyl biscoumacetate $\$$ or phenprocoumon\$ or warfarin $\$$ or ancrod\$ or citric acid\$ or coumadin or coumarin\$ or chromonar $\$$ or coumestro $\$$ or dicoumarol or esculi or ochratoxin $\$$ or umbelliferone\$ or dermatan sulfate or dextran\$ or edetic acid\$ or enoxaparin $\$$ or gabexate\$ or heparan or heparin $\$$ or idraparinux or Imwh\$ or nadroparin\$ or pentosan sulfuric polyester\$ or phenindione\$ or phenylindandione or protein c or protein s or rivaroxaban or tedelparin $\$$ or ximelagatran).tw.

12. (argatroban or certoparin or dalteparin or tinzaparin or parnaparin or reviparin or danaparoid or lomoparan or org 10172 or mesoglycan or polysaccharide sulphate\$ or sp54 or sp-54 or md805 or md-805 or cy222 or cy-222 or cy216 or cy-216 or DU-176 or YM150).tw.

13. (Marevan or Fragmin\$ or Fraxiparin\$ or Klexane).tw.

14.exp Pipecolic acids/ae, tu

15.exp Vitamin K/ai

16.Vitamin $\mathrm{K}$ antagonist $\$$.tw.

17.exp Antithrombins/ae, pd, de, tu

18. exp Blood coagulation factors/ai, de

19.exp Blood coagulation/de

20.(anticoagulat\$ or antithromb\$).tw.

21.or/9-20

22.8 and 21

23.Randomized Controlled Trials as Topic/

24.random allocation/

25. Controlled Clinical Trials as Topic/

26.control groups/

27.clinical trials as topic/ or clinical trials, phase i as topic/ or clinical trials, phase ii as topic/ or clinical trials, phase iii as topic/ or clinical trials, phase iv as topic/

28. double-blind method/

29.single-blind method/

30.Placebos/

31.placebo effect/

32.Therapies, Investigational/

33.Drug Evaluation/

34.Research Design/

Anticoagulation for cerebral venous sinus thrombosis (Review)

Copyright $\odot 2011$ The Cochrane Collaboration. Published by John Wiley \& Sons, Ltd. 
35.randomized controlled trial.pt.

36.controlled clinical trial.pt.

37. (clinical trial or clinical trial phase i or clinical trial phase ii or clinical trial phase iii or clinical trial phase iv).pt.

38.random\$.tw.

39.(controlled adj5 (trial\$ or stud\$)).tw.

40. (clinical\$ adj5 trial\$).tw.

41.((control or treatment or experiment $\$$ or intervention) adj5 (group\$ or subject\$ or patient\$)).tw.

42. (quasi-random $\$$ or quasi random $\$$ or pseudo-random $\$$ or pseudo random $\$$ ).tw.

43. ((singl\$ or doubl\$ or tripl\$ or trebl\$) adj5 (blind\$ or mask\$)).tw.

44. placebo\$.tw.

45. controls.tw.

46.or/23-45

47.22 and 46

48. limit 47 to humans

\section{Appendix 2. EMBASE search strategy}

Database EMBASE (Ovid)

1. exp cerebral sinus thrombosis/ or occlusive cerebrovascular disease/

2. exp cranial sinus/or brain vein/ or sinus venosus/

3. vein thrombosis/ or thrombosis/

4. 2 and 3

5. (sinus\$ or sinovenous or cerebral venous or cerebral vein\$ or cavernous or sagittal venous or sagittal vein\$).tw.

6. thrombo\$.tw.

7. 5 and 6

8. 1 or 4 or 7

9. exp anticoagulant agent/ or exp antithrombocytic agent/ or exp blood clotting inhibitor/ or exp coumarin anticoagulant/ or exp heparin derivative/

10.anticoagulant\$.tw.

11. (acenocoumarol\$ or apixaban or betrixaban or dabigatran or dicoumarol\$ or ethyl biscoumacetate\$ or phenprocoumon\$ or warfarin \$ or ancrod\$ or citric acid\$ or coumadin\$ or coumarin\$ or chromonar\$ or coumestro $\$$ or dicoumarol or esculi\$ or ochratoxin\$ or umbelliferone or dermatan sulfate $\$$ or dextran $\$$ or edetic acid\$ or enoxaparin $\$$ or gabexate $\$$ or heparan or heparin $\$$ or idraparinux or Imwh\$ or nadroparin\$ or pentosan sulfuric polyester\$ or phenindione\$ or phenylindandione or protein c or protein s or rivaroxaban or tedelparin\$ or ximelagatran).tw.

12. (argatroban or certoparin or dalteparin or tinzaparin or parnaparin or reviparin or danaparoid or lomoparan or org 10172 or mesoglycan or polysaccharide sulphate\$ or sp54 or sp-54 or md805 or md-805 or cy222 or cy-222 or cy216 or cy-216 or DU-176 or YM150).tw.

13. (Marevan or Fragmin\$ or Fraxiparin\$ or Klexane).tw.

14.Vitamin $\mathrm{K}$ antagonist $\$$.tw.

15. (anticoagulat\$ or antithromb\$).tw.

16.9 or 10 or 11 or 12 or 13 or 14 or 15

17.8 and 16

18. Randomized Controlled Trial/

19. Randomization/

20.Controlled Study/

21.control group/

22.clinical trial/ or phase 1 clinical trial/ or phase 2 clinical trial/ or phase $3 \mathrm{clinical}$ trial/ or phase $4 \mathrm{clinical}$ trial/ or controlled clinical trial/

23.Double Blind Procedure/

24.Single Blind Procedure/ or triple blind procedure/

25. placebo/

26."types of study"/

27.random\$.tw.

28. (controlled adj5 (trial\$ or stud\$)).tw.

29. (clinical\$ adj5 trial\$).tw.

30.((control or treatment or experiment\$ or intervention) adj5 (group\$ or subject\$ or patient\$)).tw.

Anticoagulation for cerebral venous sinus thrombosis (Review)

Copyright (c) 2011 The Cochrane Collaboration. Published by John Wiley \& Sons, Ltd. 
31. (quasi-random $\$$ or quasi random $\$$ or pseudo-random $\$$ or pseudo random $\$$ ).tw.

32. ((singl\$ or doubl\$ or tripl\$ or trebl\$) adj5 (blind\$ or mask\$)).tw.

33. placebo\$.tw.

34.controls.tw.

35.or/18-34

36.17 and 35

37.limit 36 to human

\section{Appendix 3. Cochrane Central Register of Controlled Trials search strategy}

Cochrane Central Register of Controlled Trials (The Cochrane Library 2011, Issue 1)

\#1.MeSH descriptor Intracranial Embolism and Thrombosis this term only

\#2.MeSH descriptor intracranial thrombosis this term only

\#3.MeSH descriptor Sinus Thrombosis, Intracranial explode all trees

\#4.MeSH descriptor cerebral veins this term only

\#5.MeSH descriptor cranial sinuses explode all trees

\#6.(\#4 or \#5)

$\# 7 . \mathrm{MeSH}$ descriptor thrombosis this term only

\#8.MeSH descriptor venous thrombosis this term only

\#9.(\#7 or \#8)

$\# 10$.(\#6 and \#9)

\#11.(sinus* in All Text or sinovenous in All Text or "cerebral venous" in All Text or "cerebral vein ${ }^{\star "}$ in All Text or cavernous in All Text or "sagittal venous" in All Text or "sagittal vein*" in All Text)

$\# 12$.thrombo* in All Text

\#13.(\#11 and \#12)

\#14.(\#1 or \#2 or \#3 or \#10 or \#13)

$\# 15 . \mathrm{MeSH}$ descriptor anticoagulants explode all trees

\#16.anticoagulant* in All Text

\#17.(acenocoumarol* in All Text or apixaban in All Text or betrixaban in All Text or dabigatran in All Text or dicoumarol* in All Text or "ethyl biscoumacetate*" in All Text or phenprocoumon* in All Text or warfarin* in All Text or ancrod* in All Text or "citric acid*" in All Text or coumadin* in All Text or coumarin* in All Text or chromonar ${ }^{*}$ in All Text or coumestro* in All Text or dicoumarol in All Text or esculi* in All Text or ochratoxin* in All Text or umbelliferone* in All Text or "dermatan sulfate*" in All Text or dextran* in All Text or "edetic acid*" in All Text or enoxaparin ${ }^{\star}$ in All Text or gabexate* in All Text or heparan in All Text or heparin* in All Text or idraparinux in All Text or Imwh* in All Text or nadroparin* in All Text or "pentosan sulfuric polyester*" in All Text or phenindione* in All Text or phenylindandione in All Text or "protein c" in All Text or "protein s" in All Text or rivaroxaban in All Text or tedelparin* in All Text or ximelagatran in All Text)

\#18. (argatroban in All Text or certoparin in All Text or dalteparin in All Text or tinzaparin in All Text or parnaparin in All Text or reviparin in All Text or danaparoid in All Text or lomoparan in All Text or "org 10172" in All Text or mesoglycan in All Text or "polysaccharide sulphate*" in All Text or sp54 in All Text or sp-54 in All Text or md805 in All Text or md-805 in All Text or cy222 in All Text or cy-222 in All Text or cy216 in All Text or cy-216 in All Text or DU-176 in All Text or YM150 in All Text)

\#19.(Marevan in All Text or Fragmin* in All Text or Fraxiparin* in All Text or Klexane in All Text)

\#20.MeSH descriptor pipecolic acids explode all trees with qualifiers: TU,AE

\#21.MeSH descriptor vitamin k explode all trees with qualifiers: Al

\#22."Vitamin K antagonist ${ }^{\star \prime}$ in All Text

\#23.MeSH descriptor antithrombins explode all trees with qualifiers: AE,PD,DE,TU

\#24.MeSH descriptor blood coagulation factors explode all trees with qualifiers: Al,DE

\#25.MeSH descriptor blood coagulation explode all trees with qualifiers: DE

\#26.(anticoagulat* in All Text or antithromb* in All Text)

$\# 27$. (\#15 or \#16 or \#17 or \#18 or \#19 or \#20 or \#21 or \#22 or \#23 or \#24 or \#25 or \#26)

\#28.(\#14 and \#27)

\section{FEE D B A C K}

\section{Feedback}

\section{Summary}

Feedback received for the previous version of this review, and other reviews and protocols of anticoagulants, is available on the Cochrane Editorial Unit website at http://www.editorial-unit.cochrane.org/anticoagulants-feedback

\section{WHAT'S NEW}




\begin{tabular}{lll}
\hline Date & Event & Description \\
\hline 7 March 2011 & Feedback has been incorporated & Link to feedback added. \\
\hline 21 January 2011 & $\begin{array}{l}\text { New citation required but conclusions } \\
\text { have not changed }\end{array}$ & New first author for this update. \\
\hline 21 January 2011 & New search has been performed & $\begin{array}{l}\text { We have updated the literature searches for relevant studies and } \\
\text { revised the review accordingly. We moved one study from 'Await- } \\
\text { ing classification' to 'Excluded' and added one new study as } \\
\text { 'Awaiting classification'. There is no change to the conclusions. }\end{array}$ \\
\hline
\end{tabular}

\section{HISTORY}

Protocol first published: Issue 4, 1999

Review first published: Issue 4, 2002

\begin{tabular}{lll}
\hline Date & Event & Description \\
\hline 21 July 2008 & Amended & Converted to new review format. \\
\hline
\end{tabular}

\section{CONTRIBUTIONS OF AUTHORS}

J Stam and G DeVeber initiated this review, and stimulated discussion of the correct definition of outcomes. SFTM De Bruijn and J Stam classified the outcomes, and analysed the methodology of the studies. J Stam supervised the review and wrote the final text. JM Coutinho and J Stam prepared the 2010 update of this review.

\section{DECLARATIONS OF INTEREST}

SFTM de Bruijn and J Stam were principal investigators of the CVST Study Group Trial (CVST Group 1999).

\section{SOURCES OF SUPPORT}

\section{Internal sources}

- Department of Neurology, Academic Medical Centre, University of Amsterdam, Netherlands.

\section{External sources}

- No sources of support supplied

\section{INDEX TERMS}

\section{Medical Subject Headings (MeSH)}

Anticoagulants [adverse effects] [*therapeutic use]; Fibrinolytic Agents [adverse effects] [^therapeutic use]; Heparin [adverse effects] [*therapeutic use]; Nadroparin [adverse effects] [ ${ }^{\star}$ therapeutic use]; Randomized Controlled Trials as Topic; Risk; Sinus Thrombosis, Intracranial [*drug therapy]

\section{MeSH check words}

Humans 